\title{
Optimal Positive End-Expiratory Pressure Therapy in Infants and Children with Acute Respiratory Failure ${ }^{1}$
}

\author{
MADOLIN K. WITTE, SHARON A. GALLI, ${ }^{2}$ ROBERT L. CHATBURN, AND \\ JEFFREY L. BLUMER \\ Divisions of Pediatric Pharmacology and Critical Care and Pediatric Respiratory Therapy, Rainbow Babies \& \\ Childrens Hospital and Departments of Pediatrics and Pharmacology, Case Western Reserve University, \\ Cleveland, Ohio 44106
}

\begin{abstract}
Positive end-expiratory pressure (PEEP) has become a mainstay in the treatment of hypoxemic acute respiratory failure (ARF). Whereas PEEP improves arterial oxygen tension by decreasing intrapulmonary shunting, it may also impair cardiac output and hence decrease systemic oxygen transport. Inasmuch as optimizing oxygen transport is a goal of therapy in ARF, we sought to determine if the level of PEEP that results in maximal oxygen transport could be estimated from measurements of compliance of the respiratory system $\left(\mathrm{C}_{\mathrm{rs}}\right)$ or $\mathrm{PaO}_{2}$. We studied the effects of PEEP application on cardiorespiratory parameters in $\mathbf{1 5}$ children who required mechanical ventilation for $A R F$. Static $\mathrm{C}_{\mathrm{rs}}, \mathrm{PaO}_{2}$, central venous and arterial blood pressures, indicator dilution cardiac index $(\mathrm{CI})$, and oxygen transport were determined at $0,3,6,9,12$, and $15 \mathrm{~cm} \mathrm{H}_{2} \mathrm{O}$ PEEP. $\mathrm{PaO}_{2}$ increased significantly at PEEP levels $\geq 9 \mathrm{~cm} \mathrm{H}_{2} \mathrm{O}(p<0.001)$, while $\mathrm{CI}$ fell by $15 \%$ between 0 and $15 \mathrm{~cm}$ end-expiratory pressure $(p<0.02) . \mathrm{C}^{\mathrm{rs}}$ and oxygen transport did not change significantly with increasing levels of PEEP. The level of PEEP resulting in maximal oxygen transport ranged from 0 to $15 \mathrm{~cm} \mathrm{H}_{2} \mathrm{O}$, and in all patients it corresponded to PEEP of best CI. At levels of PEEP above that associated with maximal oxygen transport, $\mathrm{CI}$ and oxygen transport fell significantly, while $\mathrm{PaO}_{2}$ continued to rise. No relationship between $\mathrm{C}_{\mathrm{rs}}$ and oxygen transport was observed. In our normovolemic patients with ARF, neither $\mathrm{PaO}_{2}$ nor $C_{r s}$ predicted PEEP of maximal oxygen transport. The decrease in CI at high levels of PEEP that prevented improvement in oxygen transport could not be detected by routine clinical monitoring of heart rate or vascular pressures. (Pediatr Res 24: 217-221, 1988)
\end{abstract}

\section{Abbreviations}

PEEP, positive end-expiratory pressure

ARDS, adult respiratory distress syndrome

CI, cardiac index

$\mathrm{C}_{\mathrm{rs}}$, compliance of respiratory system

$\mathrm{CaO}_{2}$, arterial oxygen content

CVP, central venous pressure

FRC, functional residual capacity

Received November 3, 1987; accepted April 7, 1988.

Correspondence Jeffrey L. Blumer, Ph.D., M.D., Rainbow Babies and Childrens Hospital, 2101 Adelbert Road, Cleveland, OH 44120.

Presented at the annual meeting of the Society for Pediatric Research, Anaheim, CA, May 1987

2 Present address: Division of Neonatology, Childrens Hospital National Medical Center, Washington, D.C.
PEEP has become a mainstay in the therapy of hypoxemic acute respiratory failure since its introduction for this purpose by Ashbaugh et al. in 1967 (1). In both adults and neonates with restrictive pulmonary disorders such as pneumonia, ARDS and hyaline membrane disease, PEEP has been shown to increase arterial oxygen tension (1-6) and lung volumes $(6,7)$. Furthermore, the use of this therapeutic modality has been associated with improved outcome in these patients $(1,8,9)$. However, detrimental as well as beneficial effects are associated with the use of PEEP. Adverse effects include overdistension of alveoli, resulting in increased dead space $(10)$ or alveolar rupture $(8,11)$ and cardiovascular depression $(5,6,12-14)$.

In some patients with acute respiratory failure, tissue oxygen uptake appears to be supply limited $(15,16)$. Thus, any diminution in oxygen transport may have profound physiologic consequences. Because the beneficial effects of PEEP on $\mathrm{PaO}_{2}$ may be negated by its detrimental effects on cardiac function, systemic oxygen transport may be impaired during PEEP therapy $(5,14)$. Thus, strategies must be used to titrate PEEP therapy so that its beneficial effects are not offset by its adverse effects on cardiac output.

The effects of PEEP on cardiorespiratory function in pediatric patients beyond the neonatal period have not been studied in a prospective fashion, and physiologic endpoints that define the optimal level of PEEP in individual patients have not been defined. We undertook this study to determine the effects of PEEP therapy on arterial oxygenation, compliance of the respiratory system, cardiac function, and systemic oxygen transport in children receiving mechanical ventilation for acute respiratory failure, and to identify parameter measurements that could be used to guide PEEP therapy in these patients.

\section{METHODS}

Patient population. Children admitted to the Pediatric Intensive Care Unit at Rainbow Babies and Childrens Hospital who required mechanical ventilation for acute respiratory failure characterized by arterial hypoxemia $\left(\mathrm{PaO}_{2} / \mathrm{FIO}_{2}<300\right)$ and decreased pulmonary compliance $\left(<2 \mathrm{ml} / \mathrm{cm} \mathrm{H}_{2} \mathrm{O} / \mathrm{kg}\right)$ were eligible for study. Patients with any clinical or radiographic evidence of obstructive airways disease, such as hyperinflation, wheezing, or a prolonged expiratory phase were excluded, as were those with thoracostomy tube drainage for treatment of pneumothoraces. Children with detectable airleaks around the endotracheal tube, and those in whom serial exhaled tidal volume measurements were not reproducible were also excluded. In addition, patients with systemic arterial hypotension or other evidence of hemodynamic instability were not eligible. This study was approved by the Human Investigations Committee of Uni- 
versity Hospitals of Cleveland, and informed consent was obtained from parent or guardian before study enrollment.

Arterial blood gas analysis. Arterial $\mathrm{pH}, \mathrm{PaO}_{2}$, and $\mathrm{PaCO}_{2}$ were determined by standard electrode techniques and corrected for temperature. $\mathrm{Hb}$ was measured via standard photometric methods. Oxygen saturation was calculated using the SiggardAndersen equation (17).

Hemodynamic monitoring. Central venous and arterial pressures were measured via indwelling right atrial and arterial catheters, respectively, which had been inserted for purposes of patient care. Cardiac output was measured in triplicate at each PEEP level by indocyanine green dye dilution (18) and divided by body surface area to give CI.

Measurement of compliance. Effective static compliance of the respiratory system was determined by dividing the measured exhaled tidal volume (Haloscale Respirometer, Ferraris Development and Engineering Co, Ltd., London, England) by the difference between a "plateau" pressure at end-inspiration (measured during a 2- to 3-s period of no flow) and end-expiratory pressure (7).

PEEP protocol. Before initiating the study protocol, patients were given intravenous colloid as needed to achieve a central venous pressure of $\geq 8 \mathrm{~cm} \mathrm{H}_{2} \mathrm{O}$ at zero end-expiratory pressure. End-expiratory pressures of $0,3,6,9,12$, and $15 \mathrm{~cm} \mathrm{H}_{2} \mathrm{O}$ were then applied in random order. Central venous pressure, systolic, diastolic, and mean arterial blood pressure, heart rate, arterial blood gases, serum $\mathrm{Hb}, \mathrm{Cl}$, and static $\mathrm{C}_{\mathrm{rs}}$ were measured after a 20- to 30-min equilibration period at each level of PEEP. After completion of these measurements, PEEP was changed to the next designated level. All patients were ventilated with volumecycled ventilators and PEEP was applied using the assembly specific to each ventilator. Each patient's $\mathrm{FIO}_{2}$ was kept constant for the duration of the study. Tidal volume at different levels of PEEP was not permitted to vary by more than $5 \mathrm{ml}$ to eliminate changes in compliance due to changes in tidal volume (7). Each study was completed in 3-4 h.

Calculation of arterial oxygen content and systemic oxygen transport. $\mathrm{CaO}_{2}$ was calculated using the equation: $\mathrm{CaO}_{2}=\mathrm{Hb}$ $\times 1.34 \times \mathrm{O}_{2}$ saturation $+\left(0.0031 \times \mathrm{PaO}_{2}\right)$. Systemic oxygen transport at each level of PEEP was then calculated using the equation:

$\mathrm{O}_{2}$ transport $\left(\mathrm{ml} / \mathrm{min} / \mathrm{m}^{2}\right)=\mathrm{CaO}_{2}(\mathrm{ml} /$ liter $) \times \mathrm{CI}$ (liter $/ \mathrm{min} /$ $\mathrm{m}^{2}$ )

Statistical analysis. Statistical analysis comparing data obtained at different levels of PEEP was performed using univariate analysis of variance for repeated measures and random block design analysis of variance. Correlation analysis was performed using least squares regression.

\section{RESULTS}

Patient characteristics. We studied 15 patients and their characteristics are shown in Table 1 . Four patients were $\leq 6$ months of age, two were 6-12 months of age, six were $1-5$ yr of age, and three were more than $5 \mathrm{yr}$ of age. Patients were studied $1-5$ days (mean 2.7 days) after the initiation of assisted ventilation for hypoxemic acute respiratory failure. The primary respiratory diagnosis was diffuse pneumonia in six patients, ARDS associ-

Table 1. Characteristics of study patients

$\begin{array}{ll}n & 15(8 \text { males } / 7 \text { fem } \\ \text { Median age } & 17 \text { mo, range: } 1 \text { mo- } \\ \text { Median wt } & 8.8 \mathrm{~kg}, \text { range } 3.3-80 \\ \text { Respiratory diagnoses } & \\ & \text { Pneumonia } 6 \\ & \text { ARDS } 6 \\ & \text { Hydrostatic pul- } \\ & \text { monary } \\ & \text { edema } 3\end{array}$

ated with severe anoxia/asphyxia or sepsis in six, and hydrostatic pulmonary edema secondary to left ventricular failure or volume overload in three. Cuffed endotracheal tubes were present in seven patients; no patient had a detectable airway airleak. All patients had an increased alveolar-arterial $\mathrm{O}_{2}$ gradient and decreased compliance at the time of study enrollment (Table 2).

Effect of PEEP on cardiorespiratory parameters. The effect of the application of increasing levels of PEEP on cardiorespiratory parameters is depicted in Figure 1. Mean effective static $\mathrm{C}_{\mathrm{rS}}$ did not change with the application of PEEP. In six patients, $\mathrm{C}_{\mathrm{rs}}$ was greatest at levels of PEEP $\leq 3 \mathrm{~cm} \mathrm{H}_{2} \mathrm{O}$, and in the remaining

Table 2. Initial cardiorespiratory parameters at time of study enrollment

\begin{tabular}{|c|c|c|}
\hline & Median & Range \\
\hline $\operatorname{PEEP}\left(\mathrm{cm} \mathrm{H}_{2} \mathrm{O}\right)$ & 9 & $4-13$ \\
\hline Tidal volume $(\mathrm{ml} / \mathrm{kg})$ & 12 & $8.7-18$ \\
\hline $\mathrm{FiO}_{2}(\%)$ & 40 & $30-80$ \\
\hline Compliance $\left(\mathrm{ml} / \mathrm{cm} \mathrm{H}_{2} \mathrm{O} / \mathrm{kg}\right)$ & 0.50 & $0.15-0.87$ \\
\hline $\mathrm{PaO}_{2}$ (torr) & 111 & $75-228$ \\
\hline Alveolar-arterialO $\mathrm{O}_{2}$ gradient (torr) & 134 & $74-452$ \\
\hline $\mathrm{PaCO}_{2}$ (torr) & 37 & $26-58$ \\
\hline $\mathrm{Cl}\left(\right.$ liter $\left./ \mathrm{min} / \mathrm{m}^{2}\right)$ & 3.71 & $2.1-11.2$ \\
\hline
\end{tabular}
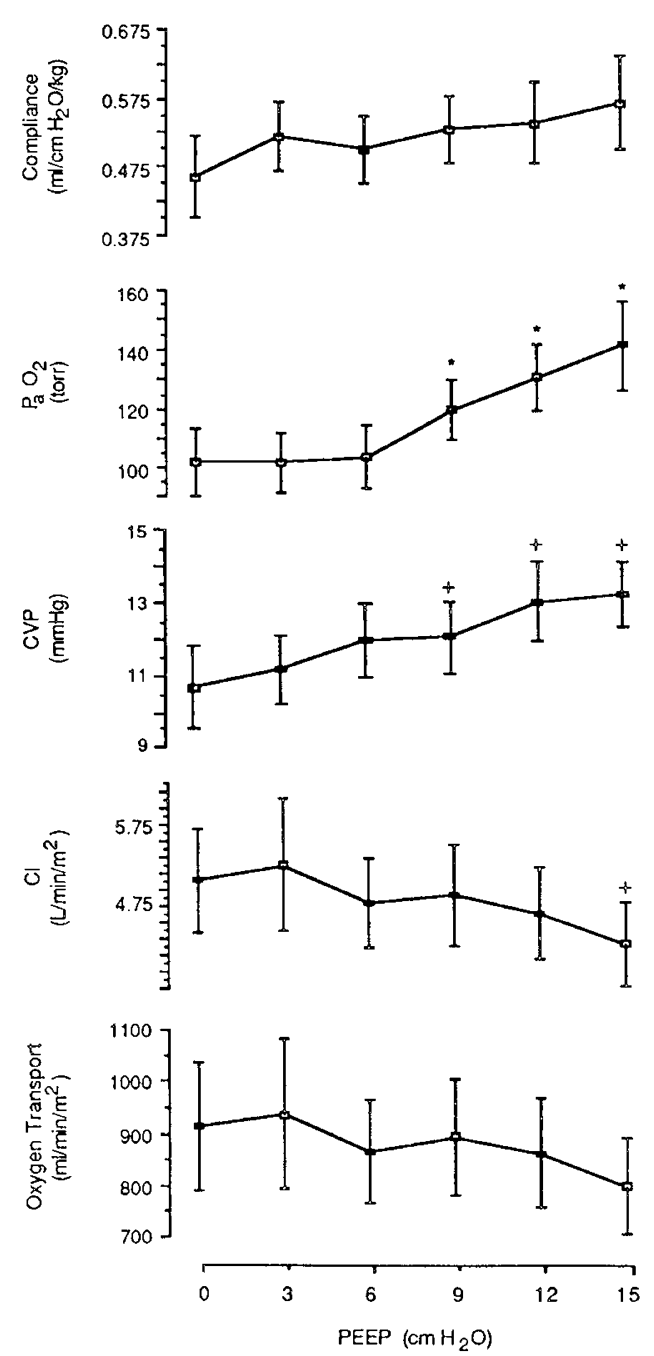

Fig. 1. Mean $\pm \mathrm{SEM}$ compliance, $\mathrm{PaO}_{2}, \mathrm{CVP}, \mathrm{CI}$, and systemic oxygen transport at increasing levels of PEEP. $\mathrm{PaO}_{2}$ and CVP increased at higher levels of PEEP. Due to a decrease in $\mathrm{CI}$, systemic oxygen transport did not change with PEEP administration. " denotes significant change from value at $0 \mathrm{~cm} \mathrm{H}_{2} \mathrm{O}$ end-expiratory pressure, $p<0.001 ;{ }^{+} p$ $<0.02$. 
nine patients the highest $\mathrm{C}_{\mathrm{rs}}$ occurred at PEEP levels $\geq 9 \mathrm{~cm} \mathrm{H}_{2} \mathrm{O}$. All three patients with hydrostatic pulmonary edema demonstrated greatest $C_{r s}$ at higher levels of PEEP; the other diagnoses were equally distributed between the two groups. No relationship was observed between changes in $\mathrm{C}_{\mathrm{TS}}$ with PEEP and the patients age or tidal volume.

Significant increases in $\mathrm{PaO}_{2}$ were observed at PEEP levels $\geq 9$ $\mathrm{cm} \mathrm{H}_{2} \mathrm{O}(p<0.001) . \mathrm{PaO}_{2}$ increased in 13 patients by an average of $46 \%$ between 0 and $15 \mathrm{~cm}$ PEEP. In two patients, both of whom showed the best $\mathrm{C}_{\mathrm{rs}}$ at lower levels of PEEP, $\mathrm{PaO}_{2}$ fell by 5 and 14\%. Mean CVP rose with increasing PEEP, from 10.7 $\mathrm{mm} \mathrm{Hg}$ at zero end-expiratory pressure to $13.3 \mathrm{~mm} \mathrm{Hg}$ at $15 \mathrm{~cm}$ $\operatorname{PEEP}(p<0.05)$.

As PEEP was increased from 0 to $15 \mathrm{~cm} \mathrm{H}_{2} \mathrm{O}$, CI fell in 13 of 15 patients, with an average decrease for all patients of $15 \%$. CI rose by 12 and $27 \%$ between 0 and $15 \mathrm{~cm} \mathrm{H}_{2} \mathrm{O}$ end-expiratory pressure in the remaining two patients whose demographics and physiologic responses to PEEP did not otherwise appear to differ from the other study patients. These hemodynamic changes were not associated with significant changes in heart rate or mean arterial blood pressure.

Despite significant increases in $\mathrm{PaO}_{2}$ at higher levels of PEEP, systemic oxygen transport at $15 \mathrm{~cm} \mathrm{H}_{2} \mathrm{O}$ PEEP was $12 \%$ lower than at zero end-expiratory pressure, due to decreasing $\mathrm{CI}$.

A strong positive correlation was observed between $C_{r s}$ measured at study enrollment and change in CVP with increasing levels of PEEP $(r=0.90, p<0.001)$. However, no relationship between $\mathrm{C}_{\mathrm{rs}}$ and changes in CI with PEEP application was observed. There was no relationship between change in $\mathrm{CI}$ and initial CVP or change in CVP with increasing PEEP. In addition, there was no correlation between tidal volume $(\mathrm{ml} / \mathrm{kg})$ and change in $\mathrm{CI}$.

Determination of "best" PEEP. For each patient, the level of PEEP coinciding with maximal oxygen transport was defined as best PEEP and was taken as a reference point for all other PEEP levels (Fig. 2). Best PEEP varied widely among patients, ranging

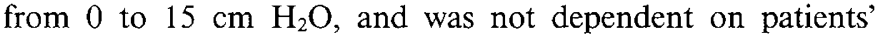
primary diagnosis, age, or tidal volume. Best PEEP coincided with maximal $\mathrm{CI}$ in all patients. At levels of PEEP above "best PEEP" CI and systemic oxygen transport fell significantly $(p<$ $0.001)$. However, $\mathrm{PaO}_{2}$ continued to rise and was significantly higher than values at best PEEP at PEEP levels $9 \mathrm{~cm} \mathrm{H}_{2} \mathrm{O}$ above best PEEP $(p<0.001)$. No consistent relationship between best PEEP and $\mathrm{C}_{\mathrm{rs}}$ was observed.

Poor concordance among levels of PEEP resulting in maximal oxygen transport, maximal $\mathrm{PaO}_{2}$, and maximal $\mathrm{C}_{\mathrm{rs}}$ was observed (Fig. 3). Maximal oxygen transport occurred at PEEP of $5.8 \pm$ $5.0 \mathrm{~cm} \mathrm{H}_{2} \mathrm{O}$ (mean $\pm \mathrm{SD}$ ), compared with $11.4 \pm 5.1 \mathrm{~cm} \mathrm{H}_{2} \mathrm{O}$ when $\mathrm{PaO}_{2}$ was highest and $8.2 \pm 6.6 \mathrm{~cm} \mathrm{H} \mathrm{H}_{2} \mathrm{O}$ when $\mathrm{C}_{\mathrm{rs}}$ was maximal.

\section{DISCUSSION}

The use of PEEP has become central to the successful management of acute respiratory failure due to restrictive lung disorders. The salutory effects of PEEP in these diseases are due to an increase in FRC through both alveolar recruitment and increase in alveolar volume (19). Whereas this improvement in FRC might be expected to increase $C_{r s}$ in patients with hypoxemic acute respiratory failure, the effect of PEEP application on $\mathrm{C}_{\mathrm{rs}}$ in previous clinical studies in this population, as in our study, has been varied $(3,5,7,14)$. In adults with ARDS, Suter et al. (3) found that the level of PEEP associated with maximal compliance ranged from 0 to $15 \mathrm{~cm} \mathrm{H}_{2} \mathrm{O}$ and was inversely correlated with the patients FRC at zero end-expiratory pressure. Thus, if PEEP increases or decreases compliance appears to depend on its relative effects to recruit atelectatic alveoli and overdistend normally aerated lung regions. The similarity of our results to findings in adults, and the lack of correlation between our
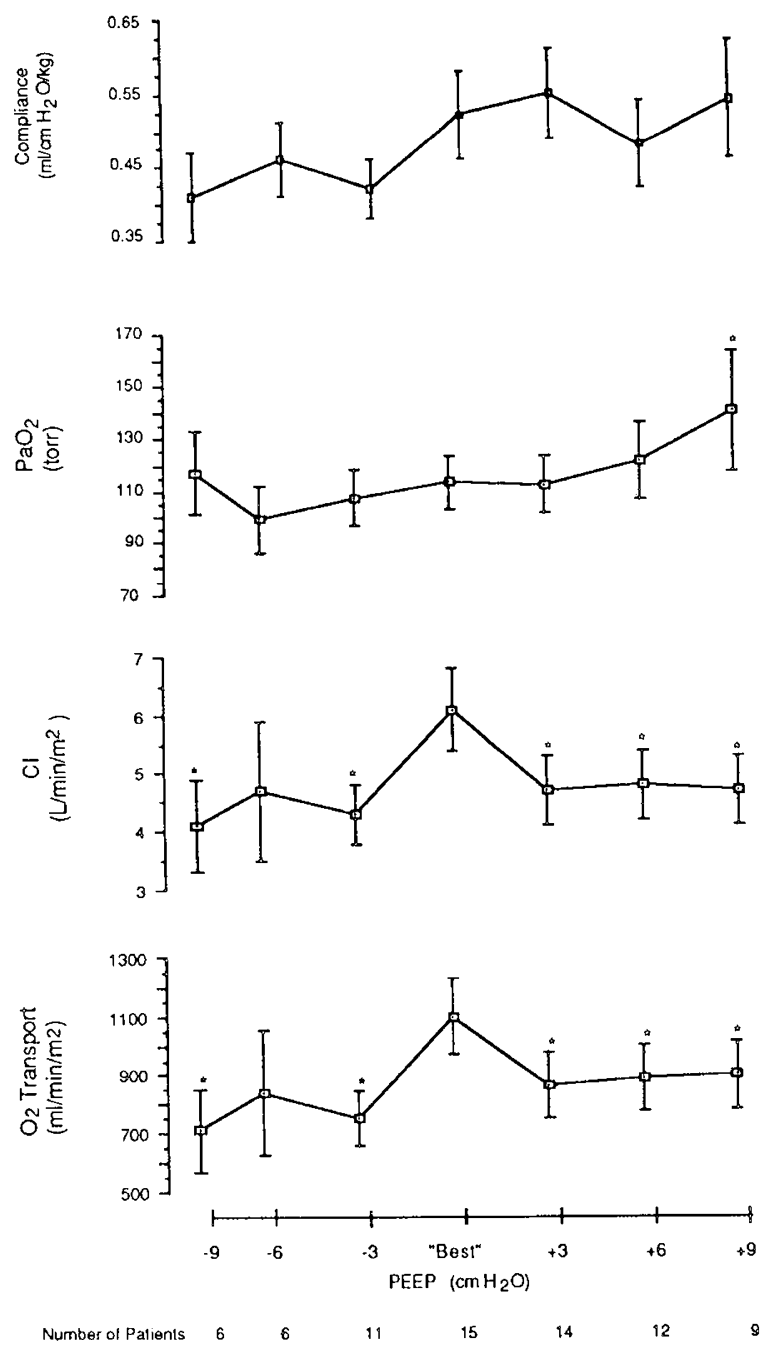

Fig. 2. Mean \pm SEM compliance, $\mathrm{PaO}_{2}, \mathrm{CI}$, and systemic oxygen transport at the level of PEEP corresponding to maximal $\mathrm{O}_{2}$ transport ("best" PEEP) and at PEEP levels above and below "best" PEEP. "Best" PEEP ranged from 0 to $15 \mathrm{~cm} \mathrm{H}_{2} \mathrm{O}$ in individual patients. At PEEP levels above "best" $\mathrm{PEEP} \mathrm{PaO}_{2}$ continued to rise, whereas $\mathrm{CI}$ and oxygen transport fell. * denotes significant difference from value at "best" PEEP, $p<0.001$.

patients age and response to PEEP, make age-related differences in pulmonary mechanics an unlikely explanation for the variable changes in $\mathrm{C}_{\mathrm{rs}}$ we observed. Although we did not measure FRC, we believe that the interpatient variation in response was due to differences in initial resting lung volumes, which could not be predicted from other clinical information.

The improvement in FRC during PEEP application also results in improved arterial oxygenation through a decrease in intrapulmonary shunting. This response to PEEP is a more consistent clinical observation that has been documented in adults with normal and diseased lungs $(1,3,5,14)$ and in neonatal patients with hyaline membrane disease $(6,8,9)$, pulmonary edema $(20)$, and meconium aspiration syndrome (4). We have shown a similar improvement in arterial oxygen tension in a group of older pediatric patients with restrictive pulmonary disorders. In our patients, significant improvement in $\mathrm{PaO}_{2}$ was observed only higher levels of PEEP ( $\left.\geq 9 \mathrm{~cm} \mathrm{H}_{2} \mathrm{O}\right)$. This observation is similar to the findings of Pollack et al. (2), who, in a retrospective review of high PEEP therapy in pediatric patients, reported that $\mathrm{PaO}_{2}$ did not improve until PEEP levels of $10 \mathrm{~cm} \mathrm{H}_{2} \mathrm{O}$ or more were used. That arterial oxygen tension does not appear to improve until higher levels of PEEP are used has important clinical 


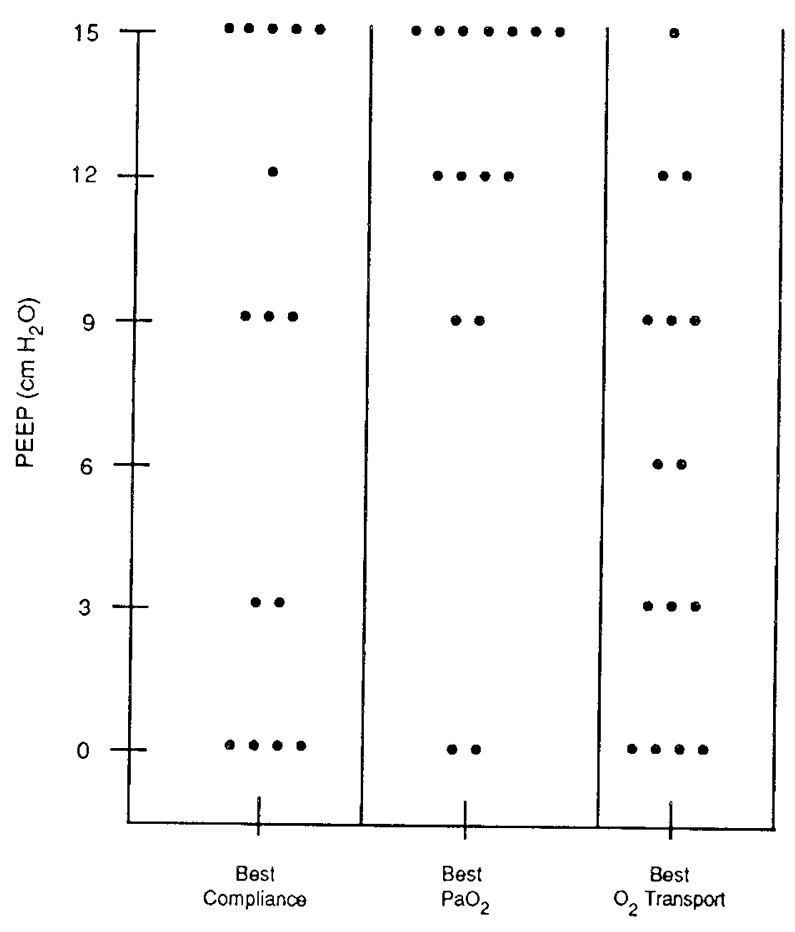

Fig. 3. Levels of PEEP resulting in best compliance, best $\mathrm{PaO}_{2}$, and best $\mathrm{O}_{2}$ transport in individual patients. $\mathrm{PaO}_{2}$ was maximal at PEEP levels $\geq 9 \mathrm{~cm} \mathrm{H}_{2} \mathrm{O}$ in 13 of 15 patients ( $87 \%$ ), whereas $\mathrm{O}_{2}$ transport was optimal at these higher levels of PEEP in only six patients (40\%).

implications, for it is at these higher levels that adverse effects on cardiac output are most likely to occur.

The application of PEEP to fully expanded areas of the lung may overdistend these lung units, thereby compressing blood vessels serving the overexpanded alveoli and diverting blood flow to poorly ventilated lung segments (10). The slight worsening of $\mathrm{PaO}_{2}$ that occurred with the application of end-expiratory pressure in two of our patients, both of whom also demonstrated best $C_{r s}$ at lower levels of PEEP, may have resulted from increased ventilation-perfusion mismatching due to overdistension of alveoli. While this atypical response to PEEP therapy could not have been predicted from the patients' clinical features or from prestudy cardiorespiratory measurements, direct measurement of FRC may have allowed us to identify these patients.

The cardiovascular depression that occurred in our patients with increasing PEEP is a well-recognized clinical phenomenon that has been reported in adults and neonates $(5,6,12-15)$. Diminished cardiac output coincident with PEEP therapy appears to be related to a number of physiologic perturbations, including reduced right heart venous return due to increased intrathoracic pressure (12), reflex cardiovascular depression caused by lung stretch $(13,21)$, interventricular septal deviation (22), decreased myocardial blood flow (23), and a circulating humoral factor released by the lung (21).

The design of our study does not allow use to define the mechanisms of cardiac output depression in our patients. The significant increase in central venous pressures paralleling the fall in cardiac output suggests that the cardiovascular depression was at least partially due to diminished venous return secondary to rising intrathoracic pressure. However, the lack of correlation between the degrees of change in CVP and CI suggests that additional mechanisms may have been operating. Because we did not measure lung volumes, we could not precisely assess the role of lung stretch on cardiac function. Schreuder et al. (13) studied the contribution of lung inflation on cardiovascular response to PEEP by comparing the hemodynamic parameters during PEEP application at different tidal volumes, and found a significantly greater diminution in cardiac output when larger tidal volumes were delivered. We did not observe a similar relationship between tidal volume and cardiovascular response to PEEP in our study.

Because reduced venous return appears to be the predominant mechanism of PEEP-associated cardiovascular depression, restoration of adequate preload by the administration of intravenous fluids can ameliorate the decline in cardiac output, as has been confirmed in clinical studies $(2,24)$. The use of colloid administration, when necessary, to achieve a CVP $\geq 8 \mathrm{~cm} \mathrm{H} \mathrm{H}_{2} \mathrm{O}$ at zero end-expiratory pressure before initiating our study protocol may have blunted the effects of PEEP on CI. It is likely that patients whose intravascular volume is depleted secondary to their underlying disease or to therapy would experience more profound cardiovascular depression with PEEP administration.

The decrease in cardiac output seen in our patients was not associated with changes in routinely measured hemodynamic parameters such as heart rate and arterial blood pressure, and thus could not have been detected without direct measurement. Similar findings have recently been reported in premature infants with severe respiratory distress syndrome in whom small increases in PEEP resulted in improved lung volumes and $\mathrm{PaO}_{2}$ but a fall in cardiac output without associated changes in systemic arterial pressure or heart rate (6).

The use of PEEP may either increase or decrease systemic oxygen delivery, depending on its relative effect to improve arterial oxygen content or decrease cardiac output. Due to the characteristics of the oxygen-Hb dissociation curve, large increases in $\mathrm{PaO}_{2}$ at oxygen tensions above 60 torr effect only small increments in arterial $\mathrm{O}_{2}$ content. Thus, as was seen in our study, significant improvements in $\mathrm{PaO}_{2}$ may be offset by proportionately smaller changes in $\mathrm{CI}$, precluding an increase in systemic oxygen transport. Although our patients were relatively normoxemic at the time of study, similar results could be expected in hypoxemic patients. Under conditions of normal $\mathrm{Hb}$, temperature, and $\mathrm{pH}$, an increase in $\mathrm{PaO}_{2}$ from 40 to 58 torr (46\% increase, as was observed between 0 and $15 \mathrm{~cm} \mathrm{H}_{2} \mathrm{O}$ PEEP in our study) would result in a $20 \%$ increase in $\mathrm{O}_{2}$ saturation from 75 to $90 \%$. Arterial $\mathrm{O}_{2}$ content would also increase by approximately $20 \%$. However, if CI simultaneously fell by $15 \%$, from 5.0 to $4.25 \mathrm{liter} / \mathrm{min} / \mathrm{m}^{2}$, systemic oxygen transport would increase by less than $2 \%$, from 510 to $518 \mathrm{ml} / \mathrm{min} / \mathrm{m}^{2}$.

Because we did not directly measure oxygen consumption or other indicators of tissue oxygenation, such as serum lactate, the physiologic significance of the small decrease in oxygen transport that we observed cannot be accurately assessed. However, even small decrements in oxygen delivery may have adverse consequences in some critically ill patients, due to an apparent pathologic dependency of tissue oxygen uptake on oxygen transport $(15,16,25)$. In normal mammalian tissue, oxygen uptake is independent of oxygen delivery over a wide range of values, and a dependency of oxygen uptake on supply is not seen until oxygen delivery falls well below normal levels (26). In contrast, in patients with ARDS, tissue oxygen uptake remains supply dependent over a wider range of oxygen delivery. In these patients, oxygen consumption may not become adequate and supply independent until oxygen delivery is increased to two to three times normal levels $(15,16)$. Similar perturbations in oxygen uptake have been observed in patients with sepsis in whom the maintenance of above-normal oxygen delivery has been associated with improved outcome (25).

The use of PEEP has improved the outcome of patients with hypoxemic acute respiratory failure and will continue to play an important therapeutic role in this setting. However, because its effects on systemic oxygen delivery may be either beneficial or detrimental, it is essential to define parameter measurements that can be used to guide the use of this therapy in individual patients. Many strategies have been proposed to titrate PEEP, and most of these have been aimed at correcting disturbances in respiratory physiology or mechanics. A common approach is to apply PEEP until hypoxemia is corrected while administering a 
nontoxic inspired oxygen fraction (27). However, as was observed in our study, high levels of PEEP may result in rising $\mathrm{PaO}_{2}$ values in the face of falling cardiac output, and thus arterial blood gases may not be an accurate reflection of oxygen transport to the tissues. Suter et al. (3) and Kuckelt et al. (28), showed in adult patients with acute hypoxemic respiratory failure, that the level of PEEP resulting in highest static compliance of the respiratory system also corresponded to best systemic oxygen transport, and suggested that this strategy could be used to optimize PEEP therapy when direct measurements of oxygen delivery were not available. Other investigators, using similar methodologies, have not found a relationship between compliance and oxygen transport $(5,29)$.

In a group of normovolemic children with hypoxemic acute respiratory failure, we have found that neither $\mathrm{PaO}_{2}$ nor compliance predicted the level of PEEP that corresponded to highest systemic oxygen transport, and thus optimizing these parameters as a guide to PEEP therapy will not ensure adequate tissue oxygenation. In a recent review of the management of ARDS in pediatric patients, the optimal level of PEEP is defined as that resulting in the highest oxygen delivery with the lowest $\mathrm{FIO}_{2}$ (30). We concur with this definition, and recommend using PEEP to attain an acceptable $\mathrm{PaO}_{2}$ with a nontoxic $\mathrm{FIO}_{2}$ while providing cardiovascular support as needed to prevent PEEPassociated depression of cardiac output. Because the detrimental effects of even high levels of PEEP on cardiac function are known to be preventable or treatable with the administration of intravascular fluids or inotropic agents, this goal is attainable. However, because the adverse hemodynamic effects of PEEP therapy cannot be reliably detected by usual clinical monitoring, direct measurements of cardiac output must be used if the goal of maintaining optimal tissue oxygen delivery is to be achieved.

Acknowledgment. The authors thank Toyoko Yamashita, Ph.D. for her assistance in statistical analysis.

\section{REFERENCES}

1. Ashbaugh DG, Bigelow DB, Petty TL, Levine BE 1967 Acute respiratory failure in adults. Lancet 2:319-323

2. Pollack MM, Fields AI, Holbrook PR 1980 Cardiopulmonary parameters during high PEEP in children. Crit Care Med 7:372-376

3. Suter PM, Fairley B, Isenberg MD 1975 Optimum end-expiratory airway pressure in patients with acute pulmonary failure. N Engl J Med 292:284 289

4. Fox WW, Berman LS, Downes JJ Jr, Peckham GF 1975 The therapeutic application of end-expiratory pressure in the meconium aspiration syndrome. Pediatrics 56:214-217

5. Klose R, Osswald PM 1981 Effects of PEEP on pulmonary mechanics and oxygen transport in the late stages of acute pulmonary failure. Intensive Care Med 7:165-170

6. Bose CL, Lawson EE, Greene A, Mentz W, Friedman M 1986 Measurement of cardiopulmonary function in ventilated neonates with respiratory distress syndrome using rebreathing methodology. Pediatr Res 20:316-320

7. Suter PM, Fairley HB, Isenberg MD 1978 Effect of tidal volume and positive end-expiratory pressure on compliance during mechanical ventilation. Chest $73: 158-162$
8. Gregory GA, Kitterman JA, Phibbs RH, Tooley WH, Hamilton WK 1971 Treatment of the idiopathic respiratory distress syndrome with continuous positive airway pressure. N Engl J Med 284:1333-1340

9. Hegyi T, Hiatt IM 1981 The effect of continuous positive airway pressure on the course of respiratory distress syndrome: the benefits of early initiation. Crit Care Med 9:38-41

10. Hedenstierna G, White FC, Mazzone R, Wagner PD 1979 Redistribution of pulmonary blood flow in the dog with PEEP ventilation. J Appl Physiol 46:278-287

11. Pollack MM, Fields AI, Holbrook PR 1979 Pneumothorax and pneumomediastinum during pediatric mechanical ventilation. Crit Care Med 7:536539

12. Cournand A, Motley HL, Werko L, Richards DL 1948 Physiologic studies on the effects of intermittent positive pressure breathing on cardiac output in man. Am J Physiol 52:162-174

13. Schreuder JJ, Jansen JRC, Versprille A 1984 Contribution of lung stretch depressor reflex to nonlinear fall in cardiac output during PEEP. J Appl Physiol 56:1578-1582

14. Lutch JS, Murray JF 1972 Continuous positive-pressure ventilation: Effects on systemic oxygen transport and tissue oxygenation. Ann Intern Med 76:193-202

15. Danek SJ, Lynch JP, Weg JG, Dantzker DR 1980 The dependence of oxygen uptake on oxygen delivery in the adult respiratory distress syndrome. Am Rev Respir Dis 122:387-395

16. Mohsenifar Z, Goldbach P, Tashkin DP, Campisi DJ 1983 Relationship between 02 delivery and 02 consumption in the adult respiratory distress syndrome. Chest $84: 267-271$

17. Siggard-Andersen $O 1980$ Determination and presentation of acid-base data Contrib Nephol 21/20:128-136

18. Miller DE, Gleason WL, McIntosh HD 1962 A comparison of the cardiac output determination by the direct fick method and the dye-dilution method using indocyanine green dye and a cuvette densitometer. J Lab Clin Med 59:345-350

19. Daly BDT, Edmonds CH, Norman JC 1973 In vivo alveolar morphometrics with positive end-expiratory pressure. Surg Forum 24:217-220

20. Galvis AG, Bensen DW 1973 Spontaneous continuous positive airway pressure (CPAP) in the management of acute pulmonary edema in infants. Clin Pediatr 12:265-269

21. Manny J, Grindlinger G, Mathe AA, Hechtman HB 1978 Positive end expiratory pressure, lung stretch, and decreased myocardial contractility. Surgery $84: 127-133$

22. Jardin F, Farcot JC, Boisante L, Curien N, Margairaz A, Bourdarias JP 1981 Influence of positive end-expiratory pressure on left ventricular performance. N Engl J Med 304:387-392

23. Venus B, Jacobs HK 1984 Alterations in regional myocardial blood flows during different levels of positive end-expiratory pressure. Crit Care Med 12:96-101

24. Walkinshaw M, Shoemaker WC 1980 Use of volume loading to obtain preferred levels of PEEP: a preliminary study. Crit Care Med 8:81-86

25. Wolf YG, Cotev S, Perel A, Manny J 1987 Dependence of oxygen consumption on cardiac output in sepsis. Crit Care Med 15:198-203

26. Shibutani K, Komatsu T, Kubal K, Sanchala V, Kumar V, Bizzarri DV 1983 Critical level of oxygen delivery in anesthetized man. Crit Care Med 11:640643

27. Nelson LD, Civetta JM, Hudson-Civetta J 1987 Titrating positive end-expiratory pressure therapy in patients with early, moderate arterial hypoxemia. Crit Care Med 15:14-19

28. Kuckelt W, Scharfenberg J, Mrochen H, Dauberschmidt R, Petrakov G, Kassil W, Meyer M 1981 Effect of PEEP on gas exchange, pulmonary mechanics, and hemodynamics in adult respiratory distress syndrome (ARDS). Intensive Care 7:177-185

29. Myers JC, Reilley TE, Vento JM, McDonald JS, Carey LC, Cloutier CT 1987 Does compliance reflect oxygen delivery in porcine septic respiratory failure treated with positive end-expiratory pressure?. Crit Care Med 15:38-40

30. Royall J, Levin DL 1988 Adult respiratory distress syndrome in pediatric patients. II. Management. J Pediatr 112:335-347 treated with positive end-expiratory pressure?. Crit Care Med 15:38-40 